of the major contributions of experimental psychology to modern philosophy of mind. Humans and monkeys with extensive damage to their primary visual cortex are clinically blind, but Weiskrantz found that they were surprisingly accurate about identifying the position and shape of objects when he forced them to guess. Philosophers, however, have not always been as appreciative of Libet's gift as they have of Weiskrantz's. Paul Churchland, Ted Honderich and Daniel Dennett, in particular, have attacked Libet's methods, results and ideas (and, in fairness, also each others'). What so vexes them is Libet's relegation of consciousness to the role of observer and occasional vetoer of action, which compromises both the cartesian view, in which the mind controls the machinery of the body, and the materialist view, where mind and brain events are identical.

Libet has replies for his critics, of course, but in developing his alternative theory, he ends up putting the ghost back in the machine in the form of a 'conscious mental field' emanating from the brain. This may be going too far, but whether or not one agrees with his thesis or not, one must acknowledge that his pioneering experimental work has certainly been stimulating.

Kevan Martin is at the Institute of

Neuroinformatics, ETH/University of Zurich,

Winterthurerstrasse 190, Zurich 8057, Switzerland.

$\cdots \cdots \cdots \cdots$

\section{A global problem}

\section{Global Change and the Earth}

System: A Planet under Pressure

by W. Steffen, A. Sanderson, P. D. Tyson,

J. Jäger, P. A. Matson, B. Moore III, F. Oldfield,

K. Richardson, H. J. Schellnhuber,

B. L. Turner II, R. J. Wasson

Springer: 2004. 336 pp. \$129, £77, €99.95

\section{Hans von Storch}

This book "focuses on the profound transformations of Earth's environment that is now apparent, a transformation owing not to the great forces of nature or to extraterrestrial sources, but to the number and activities of people - the phenomenon of global change".

The authors have adopted a systematic approach. They begin by describing the Earth system - the whole of the physical and ecological environment that determines the state of the Earth - which they view as one integrated system. Next they discuss the dynamics of the Earth system as it was before human influence: the characteristics of temporal and spatial variability, the role of biological processes, the connectivity between the different parts of the system, and the role of nonlinearities, such as the browning of the Sahara. The third chapter describes the

\title{
A world of paint
}

Visual art has one of the

longest and fullest records of

any human activity. Humans

have been recording images

of the world around them for

more than 30,000 years. In

Atlas of World Art (Laurence

King, £75), art historian John

Onians has coordinated

the work of a group

of anthropologists,

archaeologists and

art historians to

compile a temporal

and geographic

history of art.

Pictures of art, like

the African masquerade

shown here, take second

place to detailed maps

showing the cultural

influences and location of

key sites and artistic centres

on each continent in seven

different periods, from

$40,000-5,000 \mathrm{BC}$ to the

twentieth century.

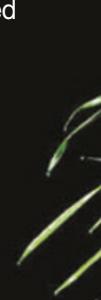

4

L.

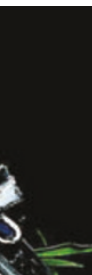

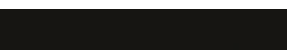

(1)
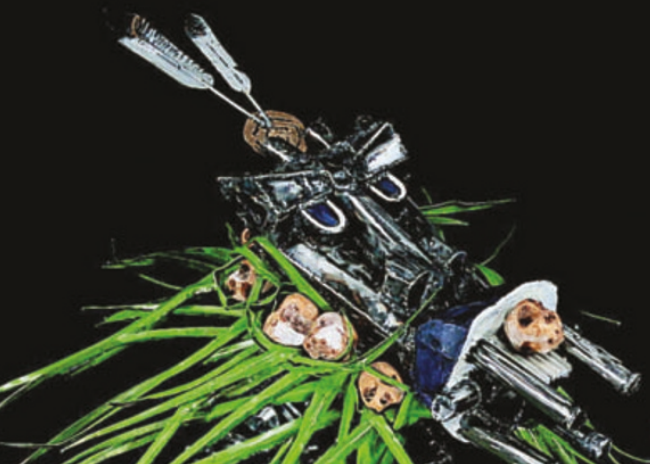

西
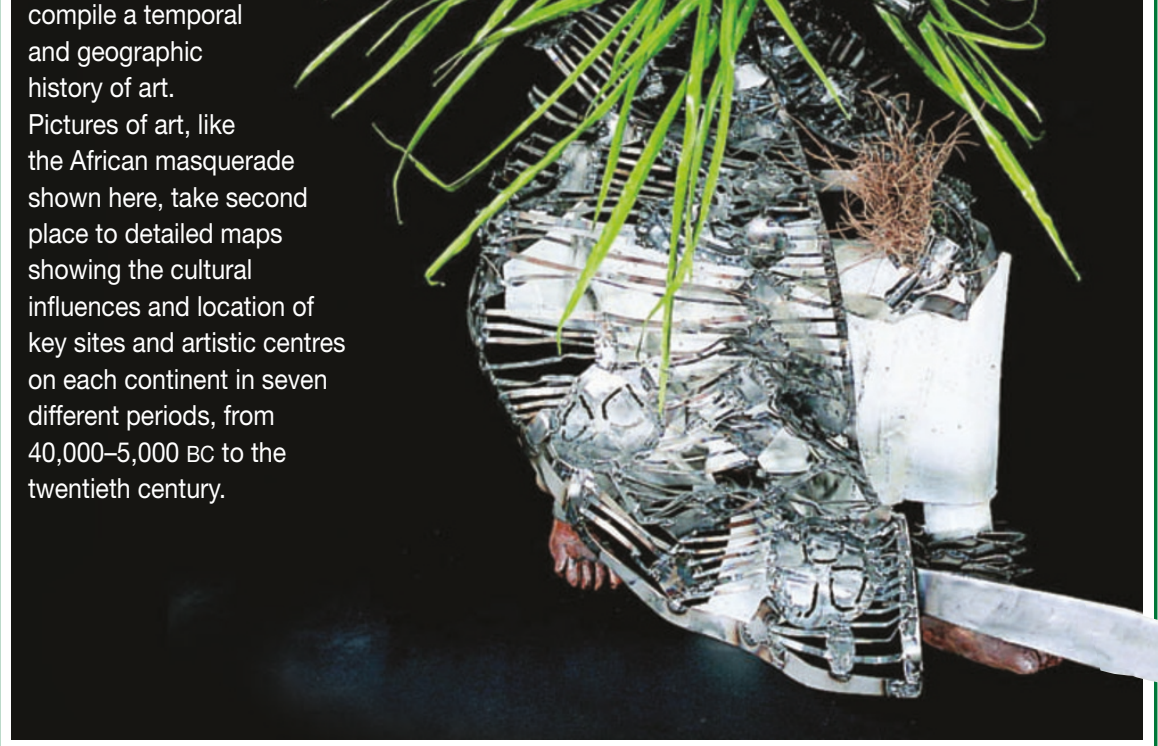

Anthropocene, the most recent part of Earth history, which has been, and continues to be, massively influenced by humans. Here the authors identify the drivers of change, characterize these changes, and put them into perspective in relation to the overall change of the Earth system. The fourth chapter then deals with the responses of the Earth system to human activities. The authors cover the entire spectrum of anthropogenic change, from emissions, changes in land use and land cover, and fires in South-east Asia, to the effect on coral reefs and the overall response of the Earth system with respect to climate and the water cycle, for example. They then examine the consequences of these changes for human well-being. The key points here relate to anticipation of future change, risks to key resources, and dangers to the Earth system as a whole. There is also a rather brief discussion of human perceptions of global change. In the final chapter, the authors draw various conclusions about the contemporary knowledge base, Earthsystem science and the need for a toolkit with which to pursue the overarching goal of global sustainability.

The book is part of a series published for the International Geosphere-Biosphere
Programme(IGBP), one of four international global environmental-change research programmes sponsored by the International Council for Science. The IGBP's objectives are "to describe and understand the interactive physical, chemical and biological processes that regulate the total Earth System, the unique environment that it provides for life, the changes that are occurring in this system, and the manner in which they are influenced by human actions".

Global Change and the Earth System is richly illustrated with many useful coloured diagrams, and numerous boxes by additional authors provide more detailed information about specific issues. However, the wealth of detail makes it hard to read, and at times the diagrams are not properly explained.

Is it a good book? I am not entirely convinced. It deals with a broader set of topics (including the number of McDonalds restaurants around the world, and the emission of heavy metals) than the Intergovernmental Panel on Climate Change (IPCC) Assessment Reports. But the IPCC reports are written by a broader community of scientists, with more diverse expertise, greater emphasis on the certainty as well as the uncertainty of knowledge, and with more convincing 
attempts either to explicate or fend off tacit value-driven concerns and opinions.

In Global Change and the Earth System, knowledge claims - that contemporary views are actually true - are often presented as definite explanations; examples include the huge extinction rate in Figure 1.7, and the reliance on the often-used but nevertheless questionable 'wiggle matching' technique. Another example is the claim that climate (in terms of an unexplained "Atmospheric Circulation Index") is the only factor that affects catches of Japanese or European sardines, with social factors, such as the Second World War, playing only a minor role. The authors often adopt the unsatisfactory practice of relating a host of changes to ongoing anthropogenic change, without systematic attempts at formal detection and attribution.

The examples that are adduced in this way seem to be biased towards deleterious effects. Thus, the book is a good demonstration that the environmental sciences are driven not only by curiosity and reductionist interests for detailed processes, but by an endeavour to integrate different sorts of often uncertain and contested knowledge claims from a broad field of disciplines - in an area that has high stakes. The result is an effort with a normative agenda of improving or saving the world.

I am sympathetic to this message, but as a scientist I think we must strive for objectivity (as far as possible) and avoid any overselling. Downplaying uncertainty is not useful, except perhaps for a limited time and a small audience. In the long term, this is not a sustainable approach. We can already see that large parts of the public and politicians, in both Europe and the United States, no longer trust many of the knowledge claims advanced by environmental scientists. Public concern about the state of the environment has begun to decline in recent years. Some may even erroneously see Bjørn Lomborg's The Skeptical Environmentalist (reviewed in Nature 414, 149; 2001) as the other side of the coin to this IGBP volume.

The authors of Global Change and the Earth System believe that "any complete analysis of the consequences of global change must go well beyond scientific and economic considerations to fundamental moral and ethical values". This is certainly true, but the book lacks an analysis of the complex history of the moral ideals in the cultural, ideological and political foundations of the modern environmental sciences. For this, readers can turn to such books as Ludwik Fleck's Genesis and Development of a Scientific Fact (University of Chicago Press, 1979) or Clarence Glacken's Traces on the Rhodian Shore (Cambridge University Press, 1967).

Hans von Storch is at the Institute for Coastal Research, GKSS Research Centre, Geesthacht 21502, Germany.

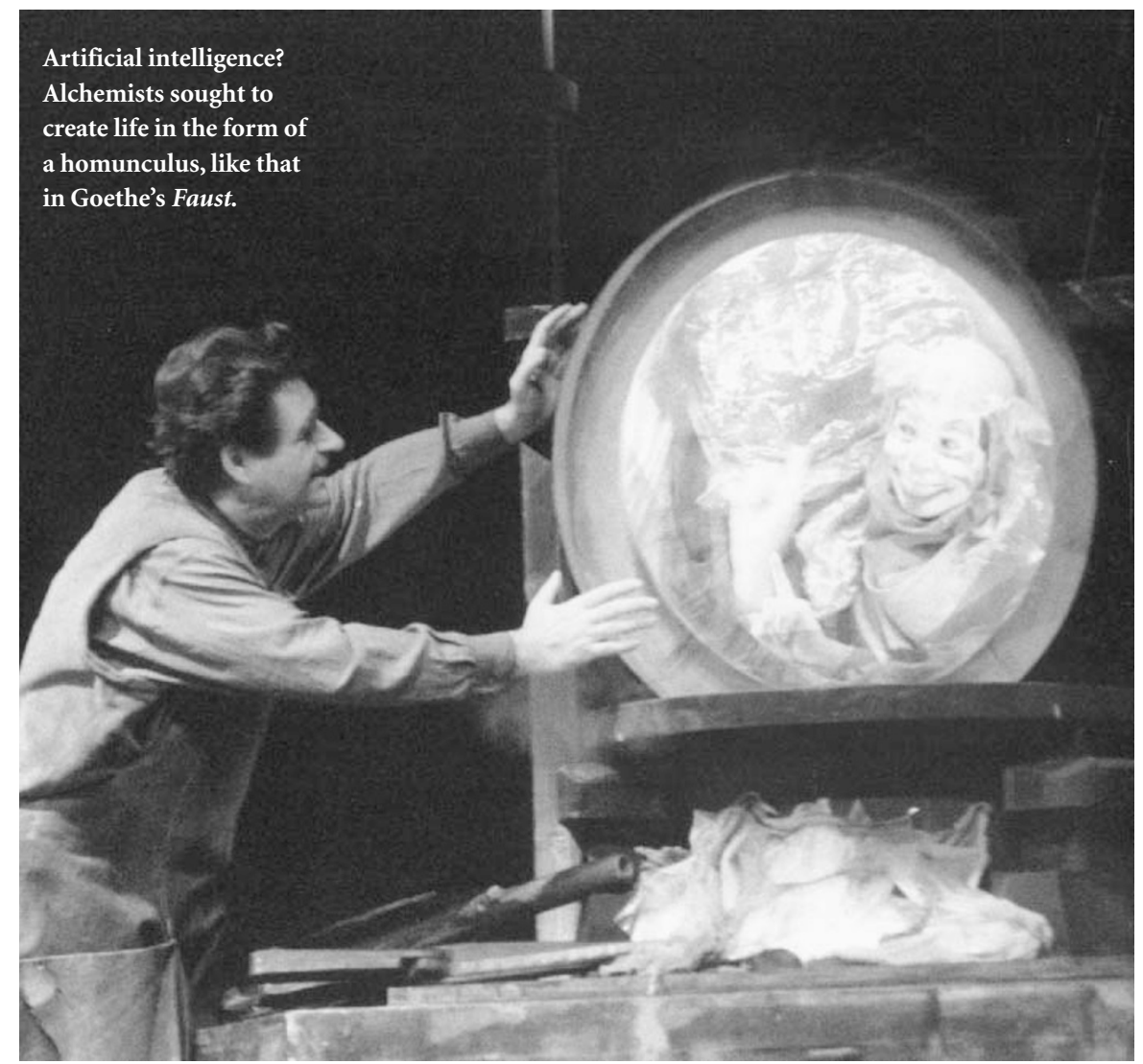

\section{Improving on nature}

\section{Promethean Ambitions: Alchemy and the Quest to Perfect Nature} by William R. Newman

University of Chicago Press: 2004. 352 pp.

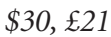

\section{David Knight}

There is nothing new under the sun, or so we are told. People worry about the artificial and the synthetic, as opposed to the natural; they pay extra for organic food, are concerned about genetic modification, and pontificate about bioethics, stem-cell research and cloning. All these things seem very modern, the fruit of progress in biochemistry, molecular biology and genetics; the oldest example would seem to be Justus Liebig's advocacy of inorganic fertilizers in the hungry 1840 s.

Not long before that, his friend Friedrich Wöhler had synthesized urea, in an attempt to provide evidence for atoms and their rearrangement, rather than to break down the organic/inorganic distinction. Processes and conditions in living organisms are very different from those in test-tubes, however, so although the end product might be the same, he did not replicate the reaction that creates urea in organisms. Human artfulness was still limited; perhaps nature was not after all a laboratory.

William Newman shows that debates about simulating, replicating and perfecting nature go back much further than this, however. Whereas we come to these debates through modern chemistry and biology, medieval and early modern authors approached them through alchemy. Modern chemists tend to look at alchemy askance, as delusion, confidence trickery or occultism, leading to disgrace, beggary and early death. But some, Michael Faraday among them, had a degree of sympathy with the idea that all the metals could not be irreducibly different indestructible entities, and Ernest Rutherford cheerfully referred to his work as modern alchemy. Newman is prominent among the historians of science who have shown how important alchemy was as part of the serious 'chymistry' of Robert Boyle, Isaac Newton and their contemporaries. In this book, he looks at the divide between 'art', which used to mean anything productive involving artifice and forethought, and 'nature', as illuminated in discussions of, and laboratory and clinical practice in, alchemy.

If something were to be made from base metal that had all the properties of gold, would it be gold? Or is there some essence that distinguishes the natural from the ersatz? Are 'species', whether of metals or of creatures, God-given and immutable?

Astronomy, contemplating the starry heavens, was well-suited to natural theology, for God could be praised for His wisdom and grandeur. But alchemy, and the practical spin-offs that led to pigments, drugs and distillates, including alcohol, seemed to be an attempt to improve the world; God 